\title{
ELECTROCERAMICS XI Reports Recent Advances and Emerging Trends in the Field www.electroceramics11.co.uk
}

Electroceramics XI, chaired by Robert Freer and Colin Leach from the University of Manchester, was held in Manchester, United Kingdom on August 31-September 4, 2008. The conference was attended by a total of 580 delegates from 41 countries, and was structured around 14 individual symposia delivering both oral and poster presentations.

Following a welcome and introduction to Manchester by Simon Gaskell, a vice president of research at the University of Manchester, the opening plenary presentation was delivered by Gary Messing of the Pennsylvania State University. Messing gave an entertaining and informed appraisal of the templated grain growth method for the production of polycrystalline piezoceramics with properties approaching those of single crystals. He presented his vision for the future of the piezoceramic industry and outlined the research needed to achieve commercially viable textured piezoelectric materials. Messing said that the commercialization of textured piezoelectrics will require advances in processing and properties of these materials. The properties of current piezoelectrics are approaching those of single crystals but still lag in piezoelectric coefficient and, more importantly, coupling coefficient. If the template particles can be aligned better, then much improved texture characteristics such as higher texture fracture and narrower orientation distribution function is expected. With current tape casting technology this requires higher aspect ratio template particles that do not reduce the materials properties like the transition and Curie temperatures, Messing said. Messing also said that a much more fundamental understanding about how the domain structure is affected by the oriented grain structure is needed.

This was followed by a second plenary presentation by Yukio Sakabe, of Murata Manufacturing Company Ltd., Japan, who discussed the history of barium titanate

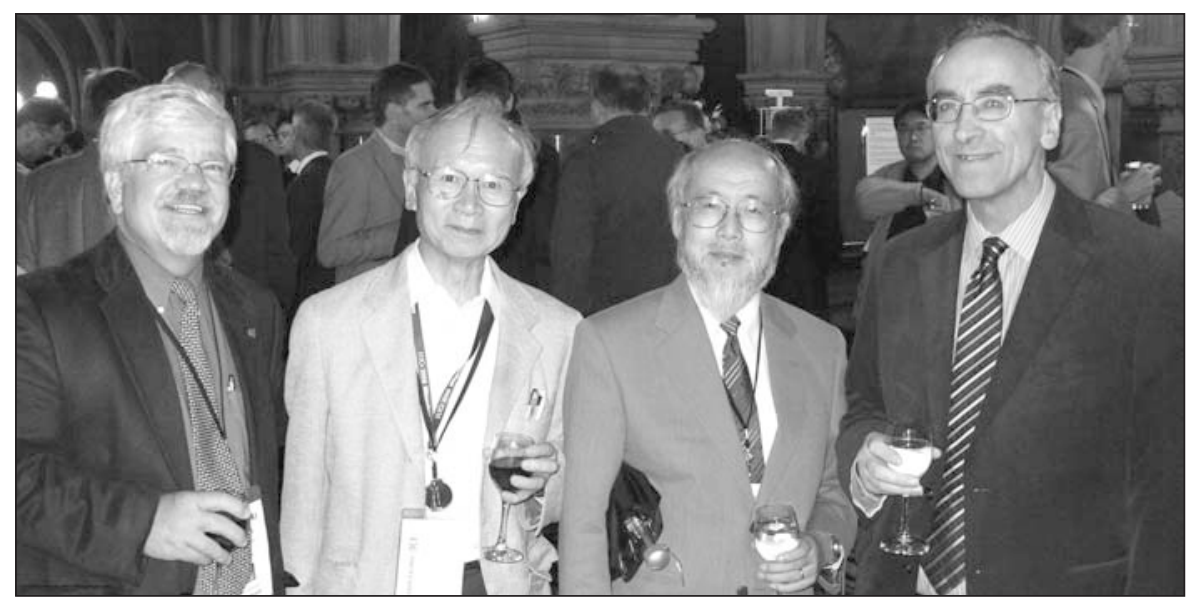

(From left to right): Gary Messing (plenary lecturer) of the Pennsylvania State University; Hitoshi Ohsato of Nagoya Institute of Technology, Japan; Masahiro Yoshimura of Tokyo Institute of Technology, Japan; and Robert Freer of the University of Manchester (co-chair of Electroceramics $\mathrm{XI}$ ) relax at a conference reception.

ceramics and their future prospects. Sakabe interwove the early history of the commercialization of $\mathrm{BaTiO}_{3}$ with the formation of Murata Ltd. in the 1940s and traced the ceramic's development through the production of fundamental electronics components, such as capacitors, thermistors, and resonators, to the present day where continuing microstructural improvements are evolving new applications, particularly in multilayer structures. Future targets include fabricating new structures on an atom-by-atom basis.

In the final plenary lecture, Joachim Maier of the Max Plank Institute at Stuttgart, Germany, discussed the relevance of nano-ionic technology for mass transport and storage applications in ceramics, balancing a review of the fundamental concepts of ionic transport processes with a discussion of the future of this technology in applications such as Li-batteries, fuel cells, and chemical sensors.
Refereed proceedings papers from this conference are scheduled to appear in the summer of 2009 in dedicated volumes of the Journal of the European Ceramic Society, the Journal of Electroceramics, Solid State Ionics, IEEE Transactions on Ultrasonics Ferroelectrics and Frequency Control, Materials Science and Technology, and Advances in Applied Ceramics.

The conference was endorsed by the Materials Research Society, and sponsored by The American Ceramic Society, The European Ceramic Society, the International Ceramic Federation, and a number of national societies. The Electroceramics conferences have been held biennually since their inception in Belgium in 1988. For more information, see Web site www.electroceramics11. co.uk.

ROBERT FREER AND COLIN LEACH University of Manchester Co-chairs, Electroceramics XI Organizing Committee

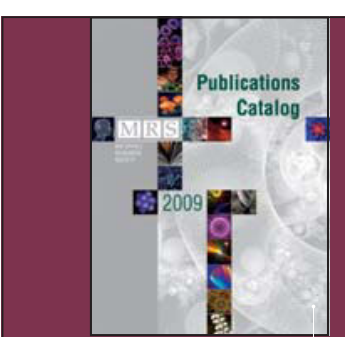

MRS Publications Catalog

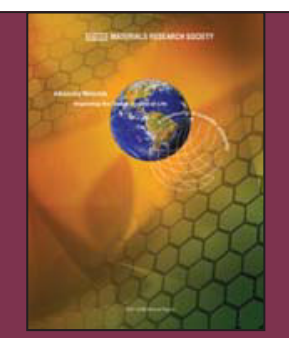

MRS Annual Report

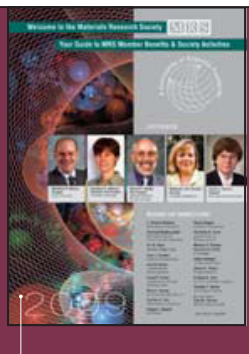

MRS Member Guide

\section{New 2009 MRS Publications}

Contact MRS today for your copy info@mrs.org 